\title{
Light and Transmission Electron Microscopic Studies on the Lingual Dorsal Epithelium of the Musk Shrew, Suncus murinus
}

\author{
By
}

\author{
Shin-ichi IWASAKI and Ken MIYATA \\ Department of Oral Anatomy, Nippon Dental University, \\ 1-8, Hamaura-cho, Niigata 951 , Japan
}

-Received for Publication, Dec. 1, 1984 --

Key Words: Suncus murinus, Tongue, Epithelium, Keratinization, Transmission electron microsocopy

\begin{abstract}
Summary: The fine structures of the lingual dorsal epithelium in the musk shrew were observed by light and transmission electron microscopy. The results showed that the lingual dorsal epithelium revealed three different cell lines by light microscopy, that is, anterior and posterior cell lines of filiform papillae and an interpapillar cell line. In the posterior cell line of filiform papillae, keratohy aline granules were not observed. Instead, tonofibrils were present in the cells of the deep intermediate layer and hard keratinized cells in the shallow intermediate and surface layers. In the anterior cell line of filiform papillae, keratohyaline granules were found in the intermediate layer. Cells in the surface layer were filled with numerous fibrous structures. Both hard and soft keratinized cells were not apparent in the interpapillar cell line.
\end{abstract}

The three dimensional structures of the mammalian tongue were first observed by Fish et al. (1944) and Kutuzov and Sicher (1951). Recently, there have been many scanning electron microscopic studies on the tongue in rats (Švejda und Skach, 1971; Yoshioka et al., 1975; Shimizu et al., 1979, 1980; Iwasaki et al., 1984a), mice (Shimizu et al., 1979; Yoshioka and Muto, 1975), guinea pigs (Arenberg et al., 1971; Ooishi et al., 1977), golden hamsters (Fujita et al., 1982a, b), chinese hamsters (Kobayashi et al., 1983) and mongolian gerbils (Iwasaki et al., 1984b) belonging to the order Rodentia, bats (Kobayashi and Shimamura, 1983) of the order Chiroptera, musk shrews (Iwasaki et al., 1983) of the order Inectivora, and mongooses (Iwasaki et al., 1984c) of the order Camivora, Histological observations of the lingual dorsal epithelium by light and transmission electron microscopy were performed mainly in members of the Rodentia such as rats (Kato and Kushida, 1965; Farbman, 1966, 1970; Yukino, 1967; Sakao, 1969; Baratz and Farbman, 1975), mice (Cameron, 1966; Cane and Spearman, 1969; Hume and Potten, 1976) and golden hamsters (Fujita et al., 1982a, b). Since there have been very few reports in mammals belonging to orders other than the Rodentia (Steflik et al., 1983), it is difficult to make a comparison of the differences in the lingual dorsal epithelium between mammals of different orders.

In the present study, one mammalian species belonging to an order other than the

This work was supported by a Grant-in-Aid for Scientific Research from the Ministry of Education, Science and Culture, Japan (No. 58771259, 1983). 
Rodentia, the must shrew (Insectivoral) was used to examine the lingual dorsal epithelium by light and transmission electron micoscopy.

\section{Materials and Methods}

Tongues from eleven male and eleven female musk shrews, Suncus murinus, weighing from 30 to $50 \mathrm{~g}$ were used. For light microscopy, tongues were removed under ether anaesthesia and fixed in Bouin's fluid. This was followed by dehydration, paraffin embedding, thin sectioning and hematoxylineosin or azan staining. For transmission electron microscopy, animals were perfused from the heart with Karnovsky fixative containing glutaraldehyde and paraformaldehyde (Karnovsky, 1965) under ether anaesthesia. The tongues were removed and refixed in the same fixative. After rinsing with $0.1 \mathrm{M}$ cacodylate buffer, the materials were post-fixed in phosphate-buffered $1 \%$ osmium tetroxide solution at $4^{\circ} \mathrm{C}$ for 1.5 hours. This was followed by dehydration, Epon-Araldite embedding, ultrathin sectioning and $\mathrm{U}-\mathrm{Pb}$ double staining. Finally, the specimens were observed under a transmission electron microscope (Hitachi $\mathrm{H}$ 500).

\section{Observations}

1. Light microscopic observations (Fig. 1) 1) Anterior cell line of filiform papillae The basal layer of this cell line consisted of almost cuboidal cells. The nuclei of these cells were round and filled with chromatin. The cells of the deep intermediate layer above the basal layer were somewhat longer along the longitudinal axis of the filiform papillae and had large nuclei which were filled with chromatin. The cells showed gradual transformation from the deep intermediate layer to the shallow intermediate layer. The cells of the latter layer became very flat along the logitudinal axis of the filiform papillae. A small number of small nuclei were observed in the cells of this layer. Various sized keratohyaline granules were widely distributed in the cytoplasm of these cells. The size of the keratohyaline granules became gradually larger and their number became smaller from the basal side to the superficial side. The form of the cells changed drastically from the shallow intermediate layer to the surface layer of this cell line. The margins of these two layers were distinctly recognized. In the surface layer, keratohyaline granules were not observed. The outline of the cells showed a spindle form along the longitudinal axis of the filiform papillae, and was not very flat. These cells main tained almost the same outline from the basal side to the free surface side. Cells near the posterior cell line of filiform papillae revealed a somewhat flat form. Small nuclei were occasionally found in this layer. In particular, there were many nuclei in the lower part of the layer near the interpapillar cell line.

2) Posterior cell line of filiform papillae

The posterior cell line was necessarily located in the secondary papillae of the connective tissue. The cells of the basal layer showed an almost cuboidal form. The cells became rapidly longer along the longitudinal axis of the filiform papillae and the nuclei of the cells in this layer tended to become fewer than in the basal layer. The cell cytoplasm in the layer revealed a deep pink colour on hematoxylin-eosin staining and a deep yellow or deep red colour on azan staining. The cells of the shallow intermediate and surface layers showed a deep red colour on azan staining and almost the same pink colour on hematoxylin-eosin staining. The nuclei located in the intermediate layer were elongated along the long axis of the filiform papillae.

3) Interpapillar cell line

The cells of the basal layer exhibited a 
cuboidal form and had a largely oval nucle us. In the intermediate layer, the cells assumed a horizontally elongated form. The nuclei of these cells also showed a largely oval form and abounded in chromatin. In the shallow intermediate layer, the cells became flatter than those in the lower layers, and the nuclei condensed. In the interpapillar cell line, small condensed nuclei were scattered in the shallow intermediate and surface layers. The cells became flatter in the surface layer than in the lower layers. In this cell line, both keratohyaline granules and keratinized cells were not observed from the basal layer to the surface layer.

2. Transmission electron microscopic observations

1) Anterior and posterior cell lines of filiform papillae

The basal cells of the anterior cell line of filiform papillae revealed a spindle form elongated along the longitudinal axis of the pipillae and contained a large nucleus. In the nucleus, chromatin areas and non-chromatin areas were mixed and a nucleolus was clearly seen. In the cytoplasm of the cells, rough surfaced endoplasmic reticulum and mitochondria were scattered. Abundant desmosomes frequently existed among the neighbouring cells. However, intercellular spaces were often present in the regions of intercellular digitations. In the deep and shallow intermediate layers of the anterior cell line of filiform papillae, large numbers of keratohyaline granules were observed (Figs. 2 and 3). In the deep intermediate layer, mitochondria, keratohyaline granules, rough surfaced endoplasmic reticulum and free ribosomes were abundant, although the keratohyaline granules were fewer in number and smaller than in the shallow intermediate layer. There were relatively wide intercellular spaces between the neighbouring cells of this layer. Each cell showed a significantly rugged surface with fine protrusion. These protrusions of neighbouring cells were linked together by desmosomes (Fig. 2). Both the number and size of the keratohyaline granules tended to increase in the cells of the shallow intermediate layer. Figures which might indicate a confusion of granules and an adherence of small granules around large ones, were observed. Abundant free ribosomes were observed as in the deep intermediate layer, although the mitochondria and rough surfaced endoplasmic reticulum were decreased compared to the deep layer. The intercellular spaces became narrow, and fine protrusions of the cells were decreased showing vacuole-like spaces between cells (Fig. 3). Relatively flat nuclei were scattered in both the deep and shallow interdmeiate layers. By transmission electron microscopy, the cells of the surface layer showed a continuous gradation from the cells of the shallow intermediate layer. In the cells of this layer, the major part of the cytoplasm was filled with medium electron dense fibrous structures, and a few small mitochondria were observed. The cell membrane was clearly recognized by its high electron density. Indistinct desmosomes lay between neighbouring cells. Extracellular substances were attached to the concave area of the cellular free surfaces (Fig. 4).

In the posterior cell line of filiform papillae, on the other hand, the basal cells revealed almost the same figure as in the anterior cell line, except for a slight elongation along the long axis of the filiform papillae. That is, the large oval nuclei were composed of chromatin and non-chromatin areas. Mitochondria, rough surfaced endoplasmic reticulum and free ribosomes abounded in the cytoplasm. In the cells of the deep intermediate layer, the sectioned cell outline showed a relatively round form except in the marginal region of this layer. There were uncertain-formed nuclei filled 
with chromatin and non-chromatin areas in the central area of the cells. Abundant ribosomes were arranged around the nuclei. In the cytoplasm except for the area adjacent to the nucleus, large numbers of tonofibrils were arranged along the longitudinal axis of the filiform papillae. The cell membrane of each cell formed spine-like protrusions in these spaces between neighbouring cells. These protrusions between neighbouring cells were combined together by desmosomes. Rough surfaced endoplasmic reticulum and small round mitochondria were scattered in the cytoplasm. The intercellular spaces between neighbouring cells were relatively wide (Fig. 5). In the cells from the shallow intermediate layer (Fig. 3) to the filiform papillar composed surface layer, almost all of the cytoplasm was filled with fibrous and amorphous structures. These two kinds of structures were irregularly miexed (Figs. 3, 6 and 7).

In the tip of the filiform papillae, fibrous structures were restricted to the cytoplasm of the outer cells. The cytoplasm of the inner cells was filled with amorphous substances (Fig. 7). Since the cell membrane except at the tip of the papillae had a high electron density, the intercellular spaces were easily recognizable. Desmosomes between neighbouring cells were clearly observed in the deep and shallow intermediate layers, and became gradually indistinct from the lower layer to the upper layer of filiform papillae.

2) Interpapillar cell line

The outline of thin-sectioned cells exhibited an oval-like shape in the basal layer of the interpapilar epithelial cell line. The large nuclei of these cells were located in the central area of the cells and were composed of chromatin and nonchromatin areas. Nucleoli were distinct in these nuclei. Abundant rough surfaced endoplasmic reticulum, free ribosomes and mitochondria were present in the cytoplasm of the cells. Undulations of the cell membranes were well-developed between neighbouring cells (Fig. 8). The cells were gradually elongated in the horizontal direction from the deep intermediate layer to the shallow intermediate layer. The nuclei located in the center of the cells were also elongated in the same direction. Abundant rough surfaced endoplasmic reticulum, free ribosomes and mitochondria were observed in the cytoplasm. The cell membranes formed many protrusions all around the cell surface. Desmosomes existed between the protrusions of neighbouring cells. Just beneath the cell membrane, odoland bodies (Wolff und Holuber, 1967) were recognized. The intercellular spaces of neighbouring cells were wide and clear (Fig. 9). Approaching the free surface of this cell line, the nuclei became gradually condensed. The major part of the cytoplasm was filled with widely spreading tonofilaments, which had a medium electron density. A few vacuolar or granular structures were scattered among these tonofilaments. The electron density of the cell membrane was higher than that of the cytoplasm. Protrusions of the cell membrane were formed all over the cell; in particular, those cells located on the free surface had significant long protrusions (Fig. 10). Fig. 11 shows a higher magnification of the surface layer near the shallow intermediate layer of the interpapillar cell line. A large nucleus was located in the center of the cells, and contained a mixture of chromatin and non-chromatin areas. The nuclear membrane was composed of a double membrane structure. Ribosomes were densely attached to almost the entire surface of the outer membrane. Pores were scattered on the nuclear membrane. The major part of the cytoplasm was filled with fine tonofilaments, and a few round mitochondria were scattered among these fila- 
mentous structures. Just beneath the free surface, the cells became significantly flattened and the nuclei were condensed to a chain of relatively large indeterminate structures of higher electron density. Small granular structures of medium electron density were attached to the above-mentioned structures. Adjacent to or near these structures, aggregates of round structures with a lower density were observed. Around these structures, ribosomes were arranged in a monolayer. Round mitochondria were seen as in the lower layer. The cytoplasm was filled with fine tonofilaments, and ribosomes were scattered among these filamentous structures. The cell membrane had a high electron density and an undulating outline (Fig. 12). Fig. 13 shows a higher magnification of a cell located on the free surface of the interpapillar epithelial cell line. No nucleus could be observed. Instead, round structures of lower electron density to which ribosomes were attached partially, were found, and granular structures of medium electron density were scattered around the above-mentioned structures. As other organelles, fine tonofilaments were densely distributed in the cytoplasm. There were a few scattered round mitochondria. The cell membrane had a high electron density and many significant protrusions. On the free surface, extracellular substances were attached to the concave areas of the protrusions. Fig. 14 shows the structures found in the tunica propria just beneath the epithelium. These structures were constituted by circularly lamellar layers. The large nucleus was restricted in one side of the outer layer. Round mitochondria were arranged circularly in the center of the lamellar structure. Pinocytotic vesicles were located on the cell membrane of the lamellae. Relatively large vacuoles and small mumbers of tiny granular structures were distributed in the cytoplasm of the lamellae. Rough surfaced endoplasmic reticulum and free ribosomes were observed around the nucleus in the outer layer. The structure was similar to Pacinian lamellated corpuscles but significantly smaller than such corpuscles.

\section{Discussion}

1. Comparison between histological structure and three dimensional structure of lingual dorsal epithelial cells in the musk shrew

Scanning electron microscopic observations of the forms of the lingual filiform papillae and epithelial cell surfaces in the musk shrew have been performed previously by Iwasaki et al. (1983). The results indicated that the filiform papillae of the musk shrew were conical in shape with a round slope from the upper rear to the lower anterior direction in the baso-frontal area, and some twigs were arranged semicircularly around the slope from the back. The fundamental form of the filiform papillae was almost identical all over the lingual body. However, the dividing part of the twigs gradually shifted to a lower part, going towards the posterior area of the lingual body. At higher magnifications, well-developed microridges were found to be widely distributed on the epthelial cell surfaces in the interpapillar area, round slope of the filiform papillae and radix zone. The microridge structures were somewhat different from each other according to the area of location. Microridges were not distinct, and relatively smooth surfaces with fine pits were formed in the upper two thirds of the anterior part and the entire surface of the lateral and posterior parts of the filiform papillae.

The present study on the lingual dorsal epithelium by light and transmission electron microscopy demonstrated that the cells of the anterior and posterior cell lines of 
filiform papillae and the in terpapillar cell line had characteristic forms in each cell line. Especially concerning the degree of keratinization, cells which showed the strongest keratinization appeared in the posterior cell line of filiform papillae, whereas such keratinized cells were not found and were replaced by keratohyaline granules, which are indicative of soft keratinization, in the cytoplasm of the anterior cell line of filiform papillae. Neither kerantinized cells nor keratohyaline granules were observed in the interpapillar cell line. This suggests that keratinization may seldom occur in the interpapillar cell line. Based on the data of the present and previous scanning electron microscopic studies, the cells on the free surface of the weakly keratinized or nonkeratinized cell lines tend to show clear microridges, whereas the cells on the free surface of the hard keratinized cell lines do not reveal clear microridges but form a relatively smooth surface with fine pores and hollows. As pointed by Takagi et al. (1976), it may be also true that microridges appear on the eptithelial cell surface in some relation to keratinization, and such structures disappear when the keratinization exceeds a certain degree. The relationship between the intracellular physiological and morphological changes and the variations in three dimensional structure of the cell surface must be examined in more detail from other points of view in the future.

2. Comparison of the degree of keratinization in musk shrews and rats

Many histological studies on the lingual dorsal epithelium of rats by light and transmission electron microscopy have been published (Kato and Kushida, 1965; Farbman, 1966, 1970; Yukino, 1967; Sakao, 1969; Baratz and Farbman, 1975). These reports indicated that the lingual dorsal epithelium of the rat was constructed mainly by anter- ior and posterior cell lines of filiform papillae and an interpapillar cell line. However, in the rat, not only the anterior cell line of filiform papillae but also the interpapillar cell line was found to contain keratohyaline granules. This means that all three cell lines had cell layers inclining towards keratinization of different degrees.

The musk shrew revealed the same structural tendency as the rat in that the lingual dorsal epithelium was composed of anterior and posterior cell lines of filiform papillae and an interpapillar cell line. However, as mentioned above, the interpapillar cell line did not show any features of keratinization or only very weak karatinization at most. One future problem is therefore to determine whether or not animals belonging to the Rodentia such as rats or mice tend to have stronger keratinization of the ligual dorsal epithelium than do animals of other orders such as musk shrews, etc.

Furthermore, comparison of the lingual dorsal epithelial surfaces as revealed by scanning electron microscopy in rats (Iwasaki et al., 1984a) and musk shrews (Iwasaki et al., 1983), demonstrates some differences between these two species. For example, as mentioned above, clear microridges were distributed in the lower half of the anterior surface of the filiform papillae and interpapillar surface of the musk shrew. However, the outline of the microridges was not so distinct in the same areas of the rat. The data may indicate that kerantinization of the epithelium is stronger in the rat than in the musk shrew.

3. Construction of each epithelial cell line The lingual dorsal epithelium of the musk shrew was found to be constructed mainly by anterior and posterior cell lines and an interpapillar cell line similar to those in the rat (Kato and Kushida, 1965; Farbman, 1966, 1970; Yukino, 1967; Sakao, 1969; 
Baratz and Farbman, 1975). The posterior cell line of filiform papillae and the interpapillar cell lines revealed continuous transformation from the basal layer to the surface layer. In the anterior cell line of filiform papillae, the cells were continuously transformed from the basal layer to the shallow intermediate layer to the surface layer was found to be drastic by light and transmission electron microscopy. That is to say, the cells from the basal layer to the shallow intermediate layer became gradually flatter and keratohyaline granules appeared by degrees; however, from the shallow intermediate layer to the surface layer, the shape of the cells changed quickly to somewhat round and keratohyaline granules disappeared at the definite marginal line. the detailed mechanisms of these drastic changes must be examined in the future.

4. Nerve endings just beneath the lingual dorsal epithelium

In the present study, structures which appeared to be somewhat allied to the inner bulb of Pacinian lamellated corpuscles (Nishi et al., 1969) were observed in the lamina propria just beneath the lingual dorsal epithelium. However, these structures did not have lamellae like the outer bulb of Pacinian lamellated corpuscles, and were therefore smaller than the corpuscles. It is presumed from the similarity in structure to the Pacinian lamellated corpuscle, however, that these structures may function as a pressure receptor. Whether or not such structures are generally distributed in other mammalian tongues must be investigated in the future.

\section{References}

1) Arenberg, I.K., Marotitz, W.F. and MacKenzie, A.P. : Preparative techniques for the study of soft biologic tissue in the scanning electron mcirscope. Tr. Am. Acad. Ophth. Otol., 75: 1333-1345, 1971.
2) Baratz, R. S. and Farbman, A. I : Morphogenesis of rat lingual filiform papillae. Am. J. Anat., 143 : 283-302, 1975.

3) Cameron, I. L. : Cell proliferation, migration, and specialization in the epithelium of the mouse tongue. J. Exp. Zool., 163: 271$284,1966$.

4) Cane, A. K. and Spearman, R. I. C.: The keratinized epithelium of the house mouse (Mus musculus) tongue: its structure and histochemistry. Arch. Oral Biol., 14: 829$841,1969$.

5) Farbman, A.I. : Morphological variability of keratohyalin. Anat. Rec., 154: 275-286, 1966.

6) Farbman, A. I. : The dual pattern of keratinization in filiform papillae on rat tongue. J. Anat., 106: 233-242, 1970.

7) Fish, H., Malone, P. P. and Richter, C.P. : The anatomy of the tongue of the domestic norway rat. I. The skin of the tongue; the various papillae; their number and distribution. Anat. Rec., 89: 429-440, 1944.

8) Fujita, K., Ohmura, S., Suzuki, N., Odajima, T. and Ohtani, T.: Morphological study on lingual dorsum of the hamster with special consideration to anatomical terms. Jpn. J. Oral Maxillofac. Surg., 28: 17-27, 1982a (Japanese).

9) Fujita, K., Ohmura, S., Okuyama, T., Odajima, T., Suzuki, N., Tateyama, M. and Matsubara, T.: Studies on morphology and structure of filiform papilla of the hamster tongue. Jpn. J. Oral Biol., 24: 453-465, 1982b (Japanese with English summary).

10) Hume, W.J. and Potten, C.S.: The ordered columnar structure of mouse filiform papillae. J. Cell Sci., 22: 149-160, 1976.

11) Iwasaki, S., Sakata, K., Mori, H., Ueno, M. and Kobayashi, K.: Ultrastructure of the lingual dorsal surface in Suncus murinus (Linne). Jpn. J. Oral Biol., 25: 471-480, 1983 (Japanese with English Summary).

12) Iwasaki, S., Miyata, K., Mori, H., Sakata, K. and-Kobayashi, K.: Fine structure of the lingual dorsal surface in rats. Acta Anat. Nippon., 59: 18-27, 1984a (Japanese with English summary).

13) Iwasaki, S., Sakata, K., Miyata, K., Mori, H. and Kobayashi, K. : Fine structure of the lingual dorsal epithelium of the mongolian gerbil. Jpn. J. Oral Biol., 26: 292-296, 1984 b.

14) Iwasaki, S., Takahashi, M., Miyata, K., Sakata, K. and Kobayashi, K. : Scanning electron 
microscopical observation of the lingual dorsal epithelial surface in mongoose, Herpestes edwardsi. Odontology (Tokyo), 71 : 1087-1097, 1984c (Japanese).

15) Karnovsky, M. J. : A formaldehyde-glutaraldehyde fixative of high osmolarity for use in electron microscopy. J. Cell Biol., 27: 137A-138A, 1965.

16) Kato, S. and Kushida, T.: An electron microscopic study on the epithelium of the rat togue. Okajimas Fol. Anat. Jpn., 40: 739$763,1965$.

17) Kobayashi, S., Shimoda, T. and Shimamura, A.: Scanning electron microscopic study on the lingual papillae of the Chinese hamster, Cricetulus griseus. Jpn. J. Oral Biol., 25: 649-655, 1983 (Japanese with English summary).

18) Kobayashi, S. and Shimamura, A.: Comparative anatomical observations of the tongue of the Japanese long-fingered bats, Mini. opterus schreibersi furiginosus. Okajimas Fol. Anat. Jpn., 58: 923-932, 1983.

19) Kutuzov, H. and Sicher, H.: The filiform and the conical papillae of the tongue in the white rat. Anat. Rec., 110: 275-288, 1951.

20) Nishi, K., Oura, C. and Pallie, W.: Fine structure of Pacinial corpuscle in the mesentery of the cat. J. Cell Biol., 43: 539-552, 1969.

21) Ooishi, M., Yoshioka, I. and Muto, H.: Surface structure of the tongue of the guinea pig with special reference to regional variations of filiform papillae. J. Aichi Med. Univ. Ass., 5: 32-35, 1977 (Japanese with English summary).

22) Sakao, N. : Light and electron microscopic studies on the differentiation of tongue epithelium in rat embryo. Sapporo Med. J., 36 : 133-158, 1969 (Japanese with English summary).

23) Shimizu, T., Kusano, T. and Wada, M.: The fine structure of the papillary epithelium on the tongue of albino rats and albino mice. Zool. Mag., 88: 188-92, 1979.

24) Shimizu, T.. Kusano, T., Wada, M. and Hara, $\mathrm{K}$.: The histochemistry and fine structure of filiform papillae in the rat tongue. Zool. Mag., 89: 53-57, 1980.

25) Steflik, D.E., Singh, B.B., McKinney, R.V. Jr. and Boshell, J.L. : Correlated TEM, SEM, and histological observations of filiform papillae of the cow tongue. Acta Anat., 117: 21-30, 1983.

26) Svejda, J.und Skach, M. : Die Zunge der Ratte im Raster-Elektronmikroskop. Z. Mikrosk. Anat. Forsch., 84: 101-16, 1971.

27) Takagi, T., Saito, H. and Aso, N.: Mechanism of the differentiation of microridges: Scanning electron microscopy of the surface structures of epithelial cells of the developing human tongue. Jpn. J. Oral Biol., 18: 418-434, 1976 (Japanese with English summary).

28) Wolff, K. und Holuber, K.: Odoland-Körper (membrane-coating granules, Keratiosomen) als epidermale Lysososomen. Arch. Klin. Exp. Derm., 231: 1-19, 1967.

29) Yoshioka, I. and Muto, H. : Scanning electron microscopic observations on the lingual papillae of the mice. J. Aichi Med. Univ. Ass., 3: 9-12, 1975 (Japanese with English summary).

30) Yoshioka, I., Mu to, H., Ozeki, N. and Ooishi, M.: Individual and local variations on filiform papillae of the rat's tongue: a scanning electron microscopic study. J. Aichi Med. Univ. Ass., 3: 216-220, 1975 (Japanese with English summary).

31) Yukino, K.: Fine structure and keratinization of the rat tongue epithelium. Sapporo Med. J., 31: 243-271, 1967 (Japanese with English summary). 


\section{PLATES}




\section{Explanation of Figures}

\section{Plate I}

Fig. 1. Light microscopic photograph of a saggittal section of the lingual dorsal epithelium of a musk shrew. A: Anterior cell line of filiform papilla. P: Posterior cell line of filiform papilla. I: Interpapillar cell line. Azan staining. $\times 300$.

Fig. 2. Transmission electron microscopic photograph of deep intermediate layer cells in the anterior and posterior cell line of a filiform papilla. The cell membrane of the cells in the anterior epithelial cell line forms many long protrusions (thick arrows). Desmosomes (thin arrows) are located in the contact area of the protrusions between two adjacent cells. Variously sized keratohyaline granules $(\mathrm{K})$ are scattered in the cytoplasm. Small round mitochondria (M), rough surfaced endoplasmic reticulum (RE) and free ribosomes are plentifully distributed. The cells of the posterior cell line (P) near the anterior one are significantly flattened. Free ribosomes and tonofibrils are densely distributed in the cytoplasm. X19000. 

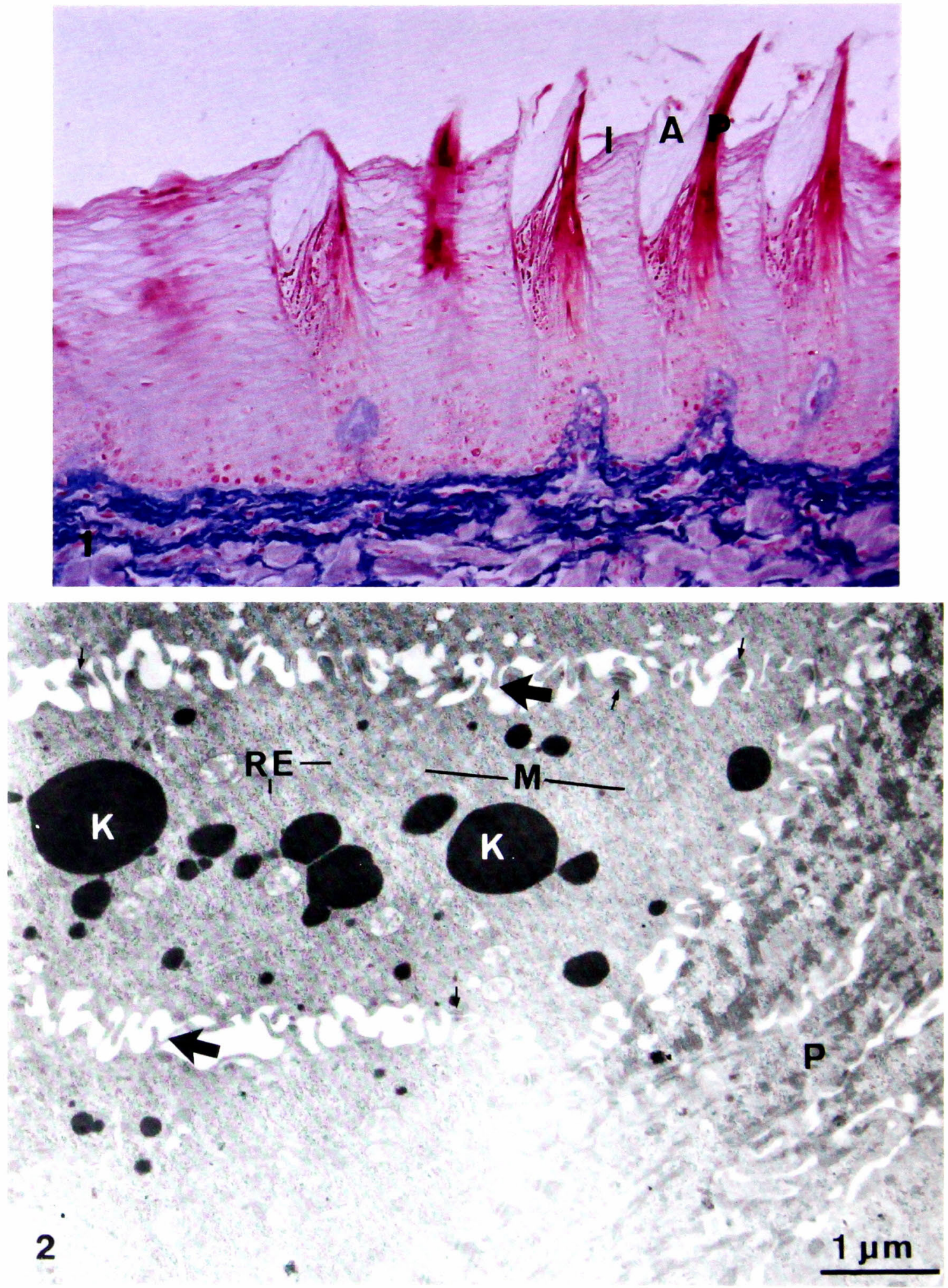


\section{Plate II}

Fig. 3. Transmission electron microscopic photograph of shallow intermediate layer cells in the anterior and posterior epithelial cell lines of a filiform papilla. The protrusions of the cell membrane and the intercellular spaces are decreased in this layer compared to the deep intermediate layer. The number and size of keratohyaline granules are increased compared to the deep intermediate layers, and some of these granules are fused together (curved arrows). Abundant fine granules (thin arrows) are attached to large granules. Free ribosomes (R) and finely fibrous structures $(F)$ are densely scattered. Keratinized cells of the posterior epithelial cell line (P) are observed adjacent to the cell of the anterior one. $\times 12000$.

Fig. 4. Surface layer in the anterior cell line of a filiform papilla. A major part of the cytoplasm is occupied by fibrous structures (Fs), and small numbers of scattered granular structures (arrow) are present. The cell membrane is abundant in undulations. Desmosomes exist between adjacent cells. Ex tracellular substances are attached to the concave areas of the free surface. $X 11500$. 


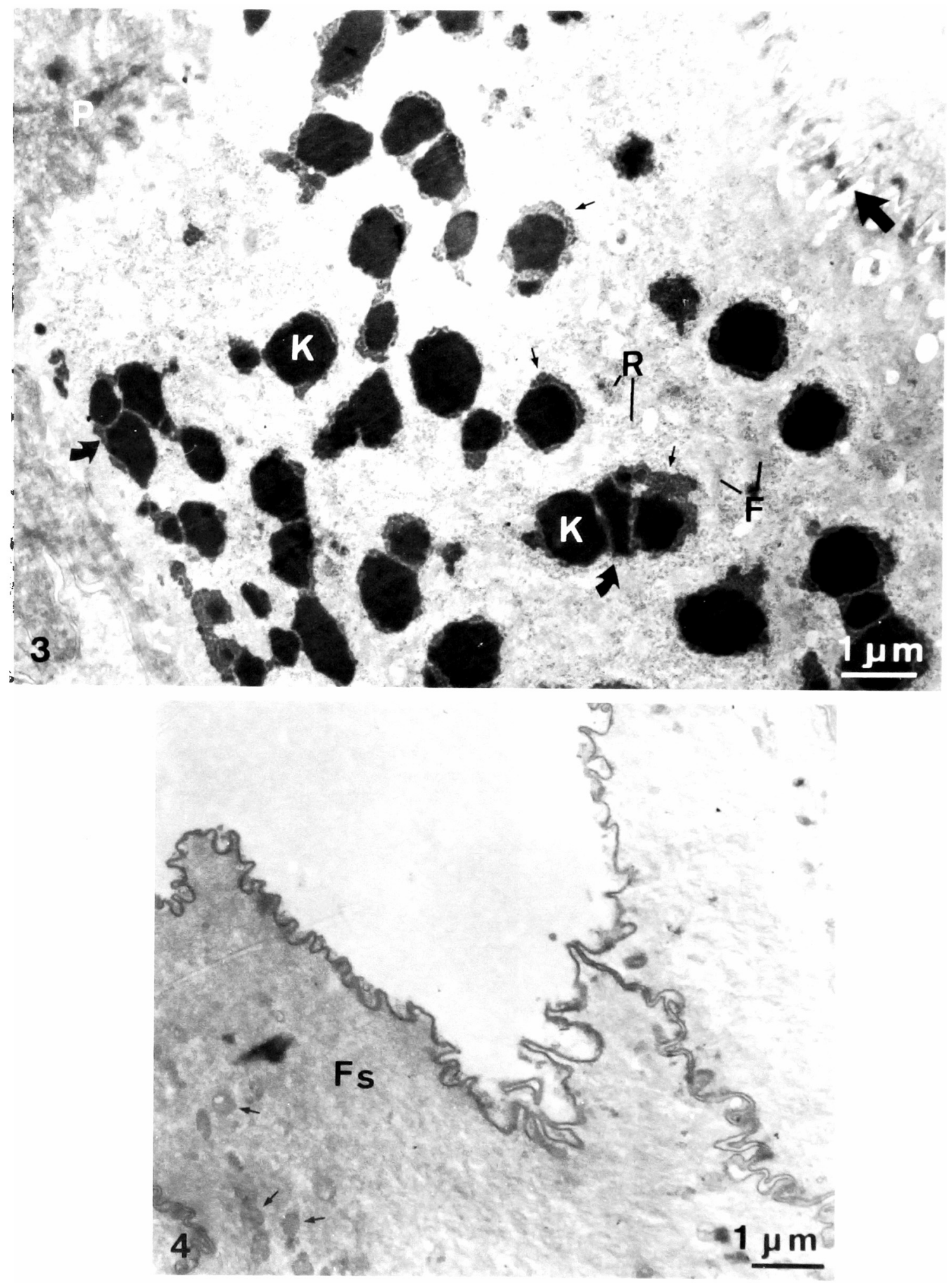




\section{Plate III}

Fig. 5. Horizontal section of surface layer cells in the posterior cell line of a papilla. The cell membrane of each cell forms spine-like protrusions. These protrusions in adjacent cells are combined by desmosomes (thin arrows). Some of the cells contained a large nucleus in the central area. High electron dense tonofilaments $(T)$ are arranged in the peripheral cy toplasm, and free ribosomes (R) are densely distributed in the central cytoplasm. A few small round granules $(G)$ are recognized. Cells which border on the anterior cell line (A) are significantly flattened. $X 8500$.

Fig. 6. Longitudinal section of the middle area of a filiform papilla. The major part of the cytoplasm is composed of fibrous (F) and amorphous (S) substances. Other organelles are not recognized. The cell membrane is tinged with high electron density and is clearly visible. The intercellular spaces are also filled with amorphous substances (arrows). $\times 28000$.

Fig. 7. Tip of a filiform papilla. A major part of the cytoplasm is occupied by homogeneously amorphous substances. The electron density of the cell membrane is high. $\times 28000$. 


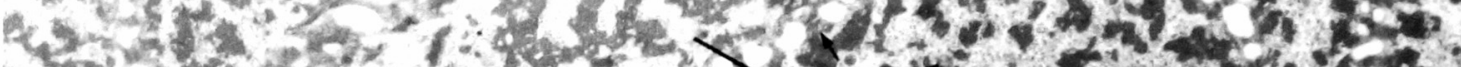

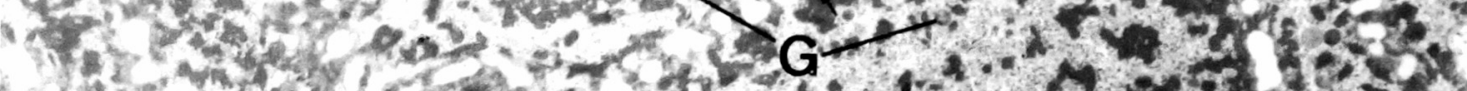

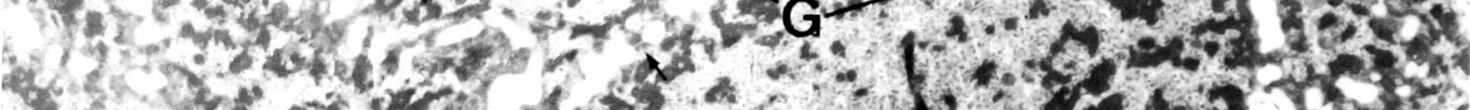

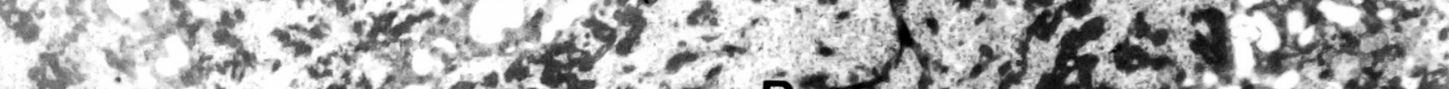

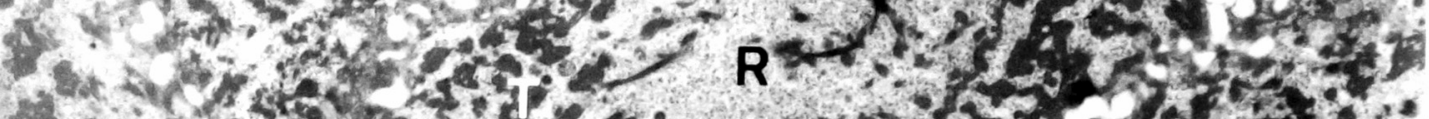

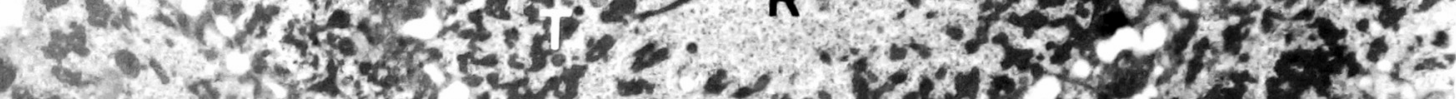

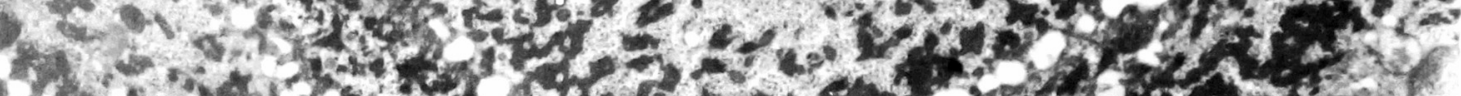

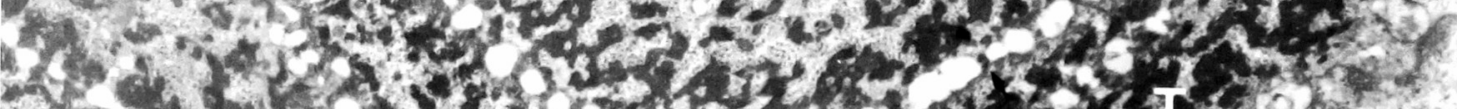

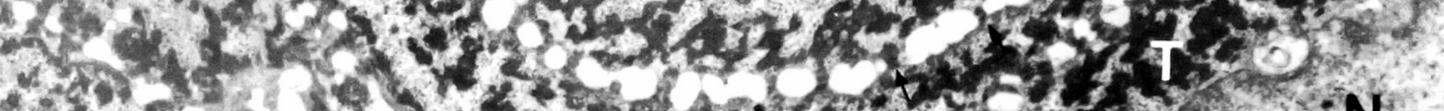

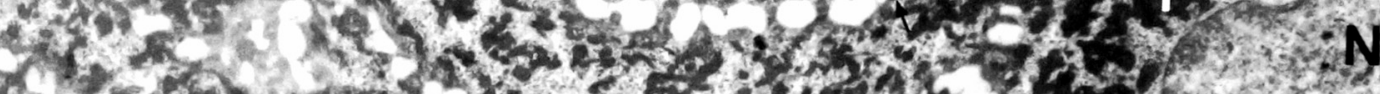

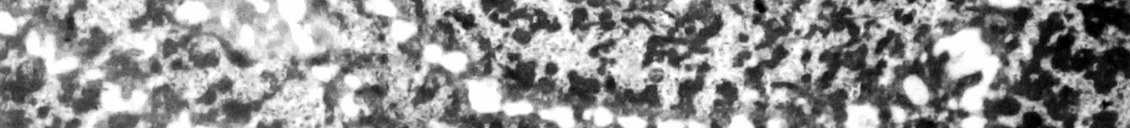

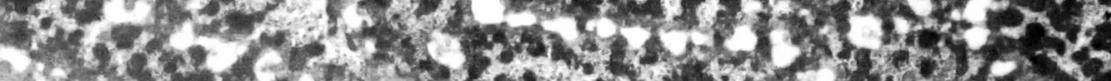

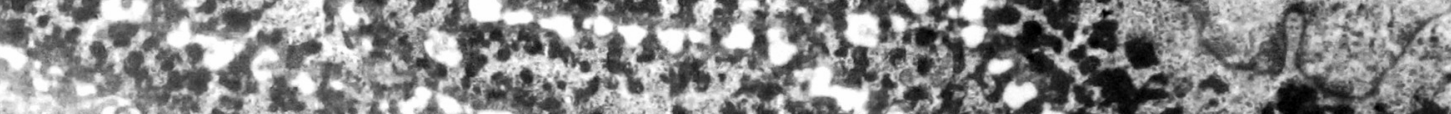

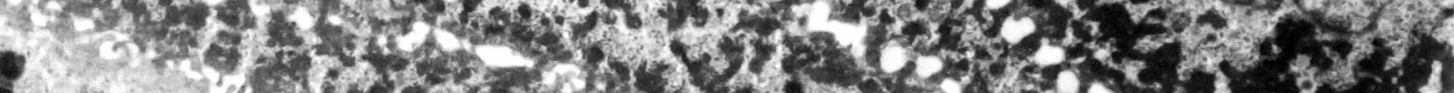

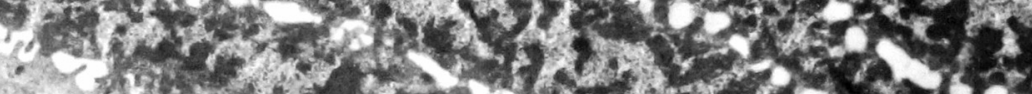
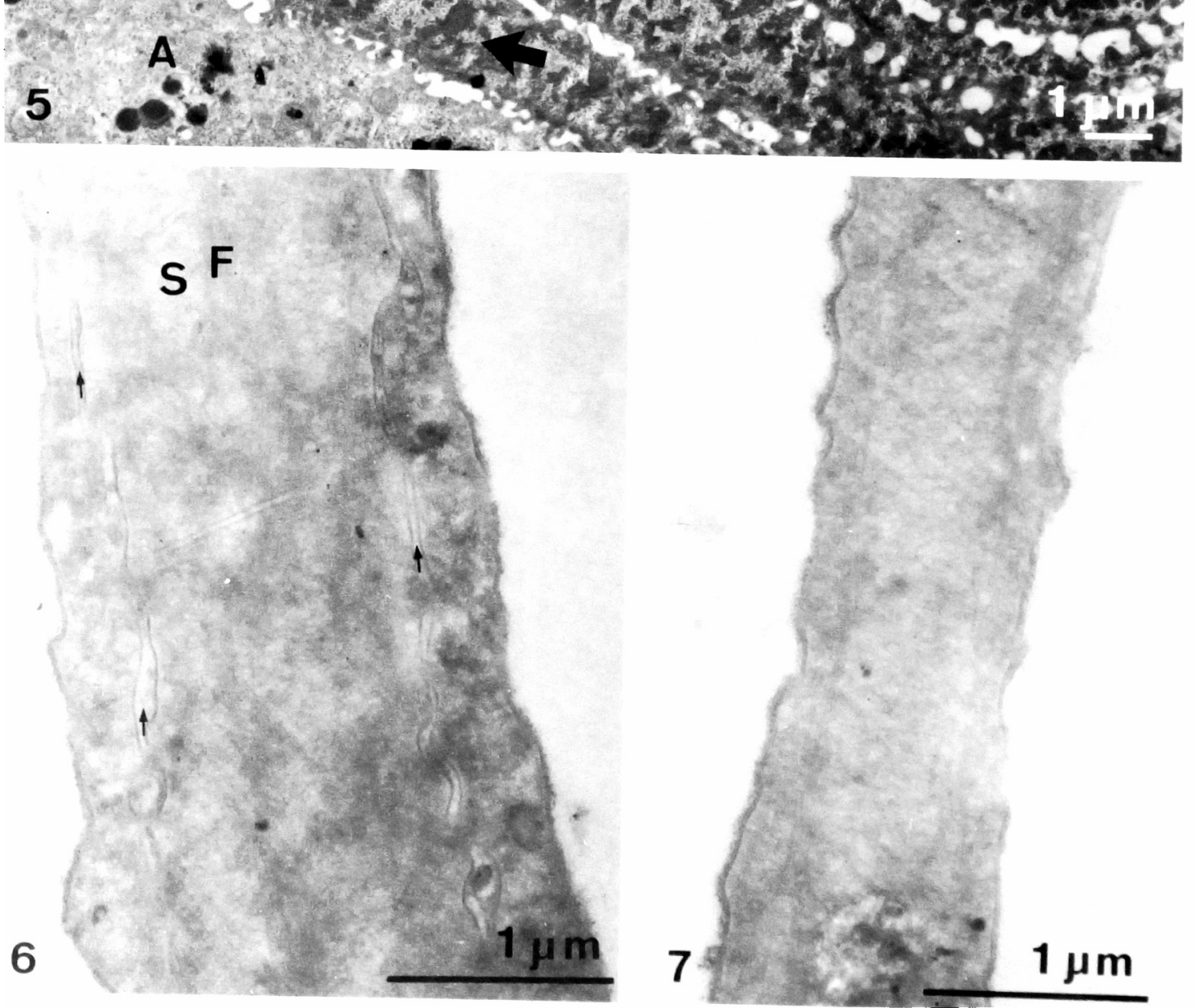


\section{Plate IV}

Fig. 8 Basal layer cells in the interpapillar epithelial cell line. The sectioned outline of cells shows an oval-like shape. A large nucleus (N) is located in the center of the cell. Rough surfaced endoplasmic reticulum, free ribosomes $(R)$ and mitochondria $(M)$ are densely distributed in the cytoplasm. The cell membrane shows significant undulations. Well-developed desmosomes lie between adjacent cells (arrows). $\times 8000$.

Fig. 9. Deep intermediate layer in the interpapillar cell line. The cell membrane undulates significantly. The protrusions of adjacent cells are combined together by desmosomes (arrows). Odoland bodies (Od) are scattered just beneath the cell membrane. $\times 8000$.

Fig. 10. Free surface in the interpapillar epithelial cell line. A major part of the cy toplasm is.occupied by tonofilaments (Tf) and homogeneously amorphous substances. There are scattered vacuolar or granular substances (arrow). The cell membrane in the free surface side undulates very significantly and has a high electron density. $\times 11500$. 

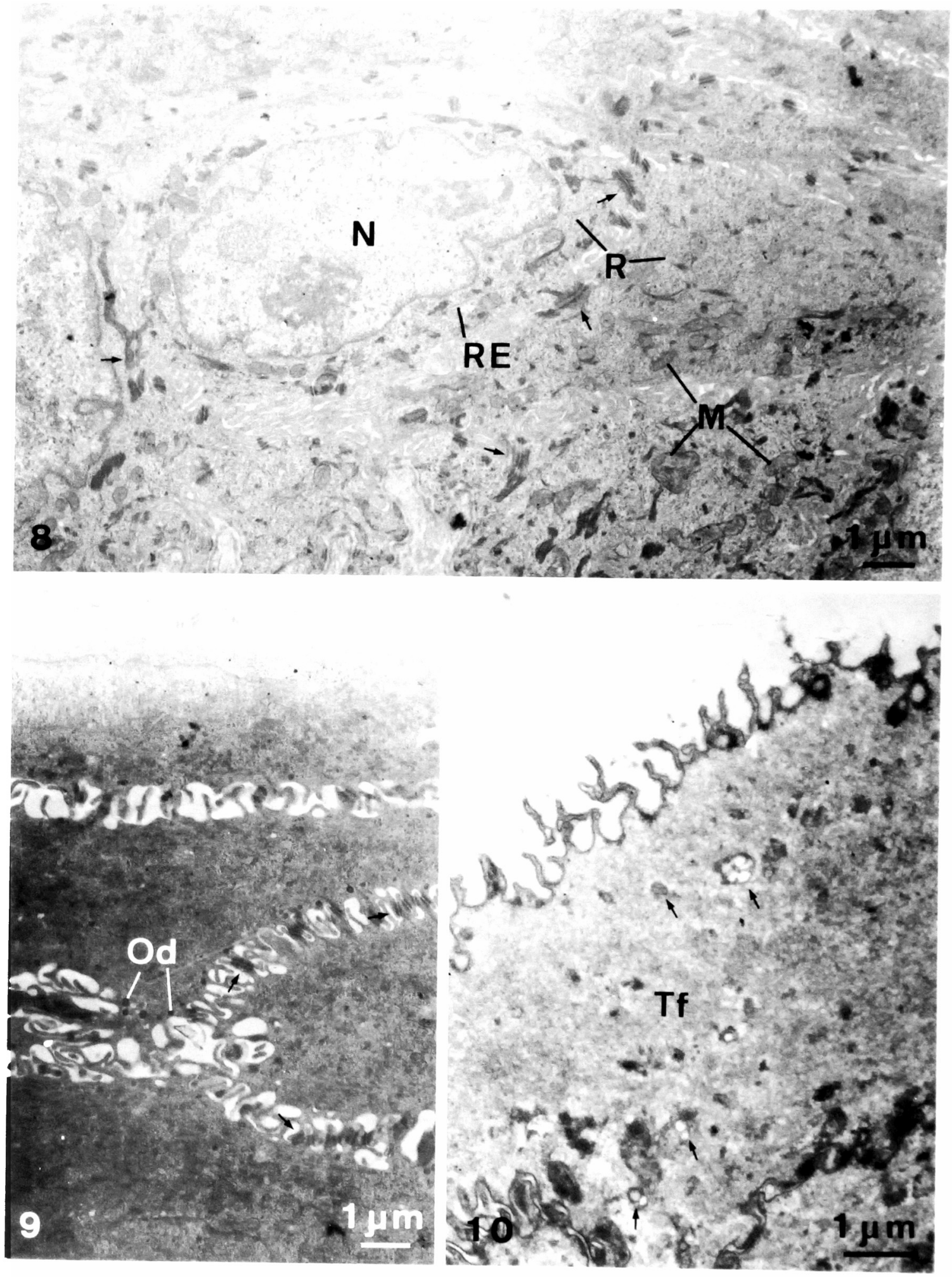


\section{Plate V}

Fig. 11 Higher magnification of surface layer cells near the shallow intermediate layer in the interpapillar cell line. The membrane of the large round nucleus is composed of a double membrane structure. Ribosomes are attached outside all around the outer membrane. Nuclear membrane pores (arrows) are seen sporadically. A major part of the cytoplasm is occupied by tonofilaments (Tf), and small numbers of round mitochondria $(M)$ are scattered among them. $\times 27500$.

Fig. 12. Cell near the free surface in the interpapillar cell line. A condensed and collapsed nucleus $(\mathrm{N})$ is located in the center of the cell. . Tonofilaments ( $\mathrm{Tf}$ ) are densely distributed in the cytoplasm, and there are scattered mitochondria. $\times 27500$. 

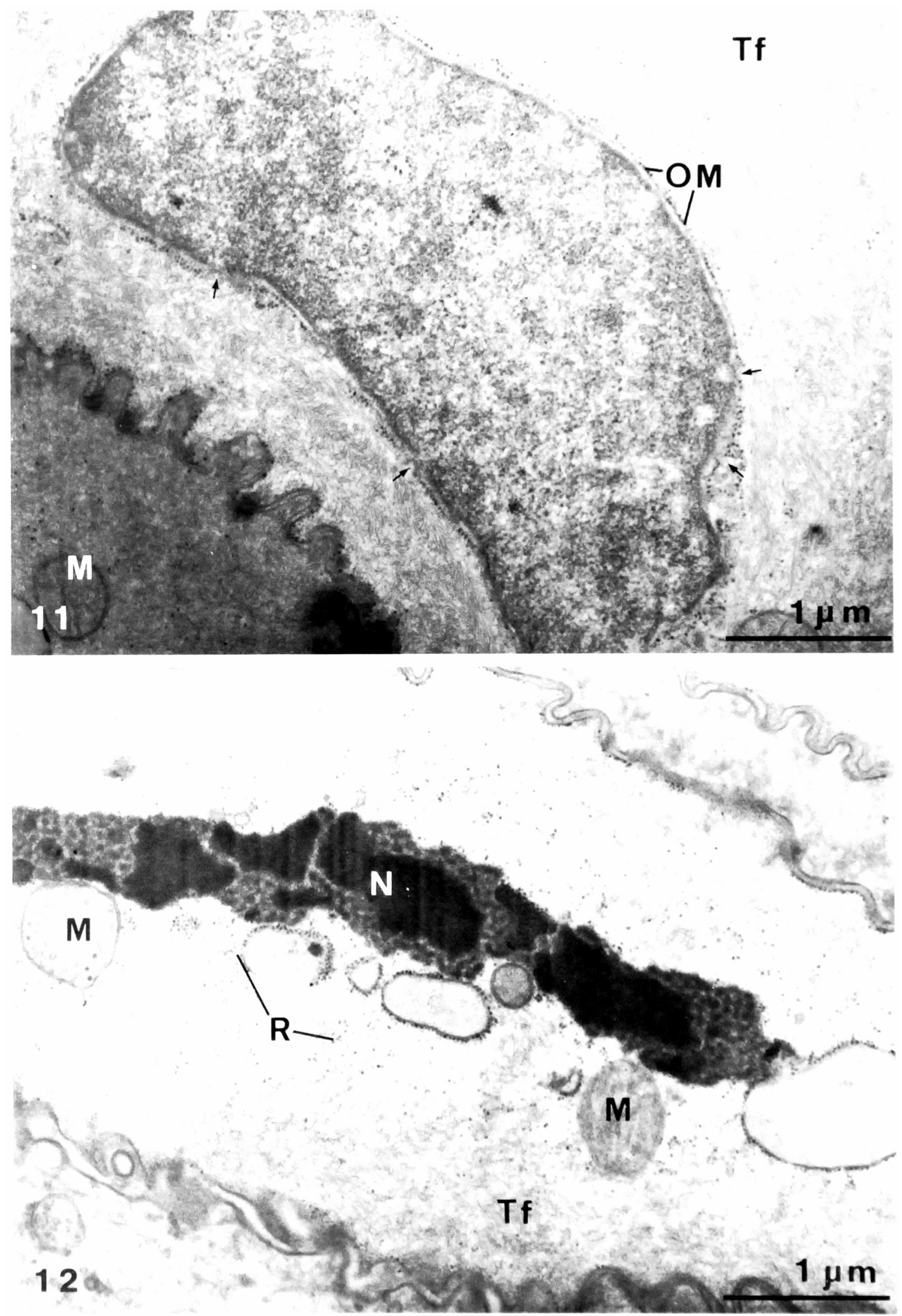


\section{Plate VI}

Fig. 13. Cell located on the free surface in the interpapillar cell line. Low electron dense round structures (asterisks) are observed, and tonofilaments (Tf) are widely distributed in the cytoplasm. there are scattered round mitochondria (M), vacuoles (B) and granular (C) substances. The cell membrane has a high electron density and significant undulations. $\times 45000$.

Fig. 14 Nerve ending found in the lamina propria just beneath the lingual dorsal epithelium showing a lamellar structure, which resembles the inner bulb of a Pacinian lamellated corpuscle. M: mitochondria. N: nucleus. Thin arrows: pinocytotic vesicles. $X 14000$. 

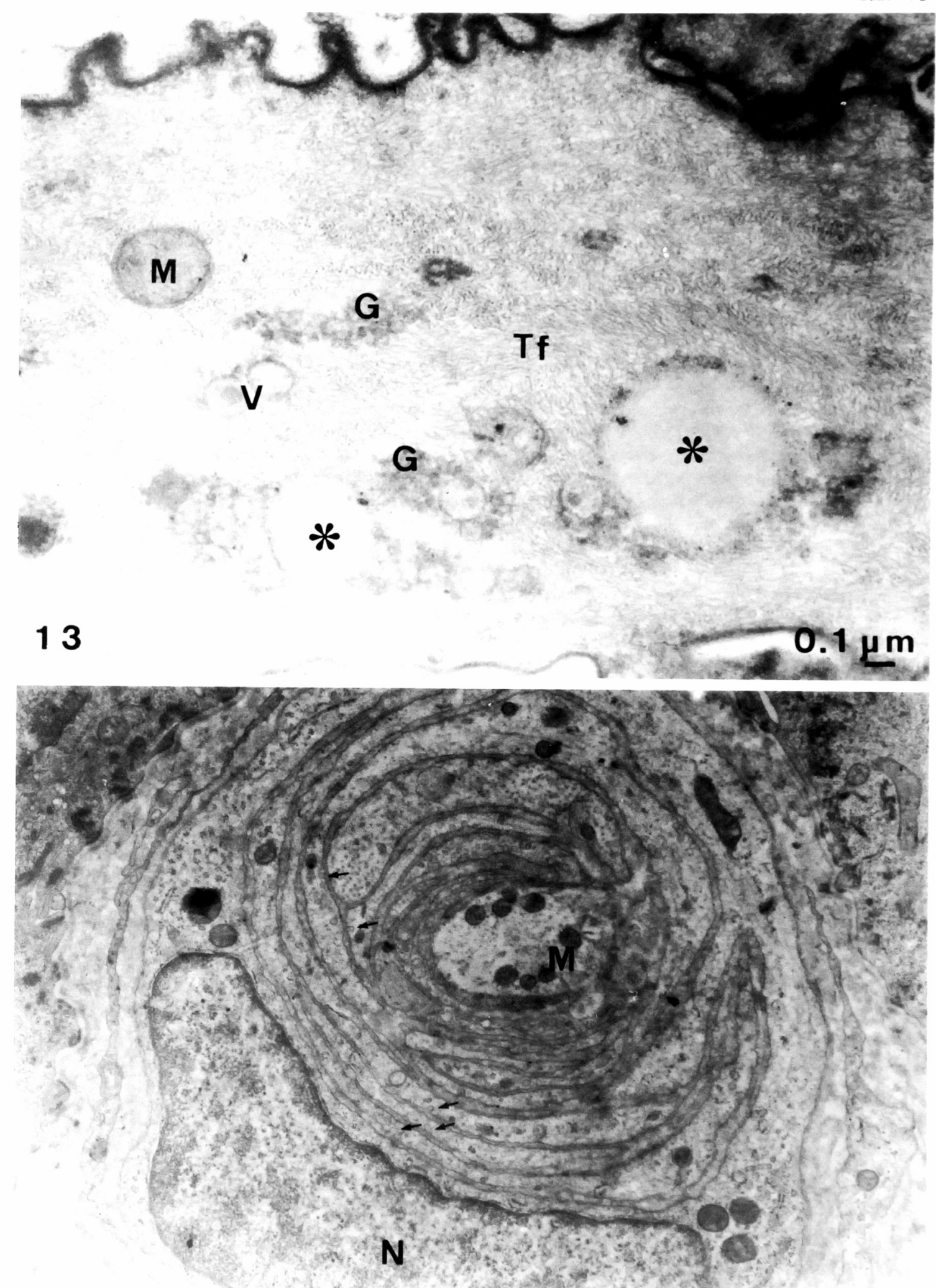